and intimate history of my father's great research work on $\alpha$-rays, for which he first became famous. These letters are only some thirty in all in a collection of several thousand from scientists all over the world.

The Cavendish collection must surely be unique as a record of the progress in physics during the past hundred years. Most of the great physicists in the Commonwealth have at some time worked in the Cavendish, and by good fortune the letters, notes and manuscripts relating to their work have been preserved in this very complete form.

\section{THE TOTAL SOLAR ECLIPSE OF FEBRUARY 25, 1952}

By Prof. R. O. REDMAN, F.R.S. The Observatories, University of Cambridge

$\mathrm{A}^{\mathrm{T}}$ $\mathrm{N}$ account of the plans to observe the total solar eclipse of February 25, 1952, has already been given in these pages ${ }^{1}$. About sixty astronomers and technicians, nearly all from Europe and the United States, were concentrated in the Sudan, and were favoured with fine weather. A few geodetic observers in Kuwait and Iraq were frustrated by cloud. It is probable that there were also parties in the field in south-east Russia and southern Siberia, but so far no reports have been received of their plans or their achievements. The full results of the work attempted are unlikely to be available for two or three years, as the ratio of measuring-time to exposure-time is often extremely high for eclipse photographs, so that the following account must be taken only as a general preliminary indication of what was done.

Using the standard meteorological records for February and March, the chances of a clear sky in the Sudan appeared to be about 95 per cent, a much more favourable figure than most eclipse tracks offer, and it was chiefly for this reason that so many astronomers decided to observe this particular eclipse. Most of them chose to go to the neighbourhood of Khartoum because it is easily accessible, has good living accommodation, and offered a reasonable amount of other facilities. Experience there during January and February suggested, however, that the weather prospects had been over-rated. An ordinary sunshine recorder can show an unbroken trace even when the sky would be considered quite bad for observations of the corona, for example, on account of cirrus cloud or dust haze, and there seemed, in fact, to be a rather large number of such imperfect days. Ultimately the chances were revised to 50 per cent good clear sky, 5 per cent too bad for any optical observations, and 45 per cent of quality varying between these extremes. During the weeks of preparation, all observers were troubled to some extent by heat and dust, although there was no really bad 'haboob'. 'The daily maximum shade temperature varied between $28^{\circ}$ and $41^{\circ} \mathrm{C}$., the average diurnal range being about $17^{\circ} \mathrm{C}$.; the humidity was extremely low. The day of the eclipse was cool, and the sky almost completely clear, although not perfectly transparent. A fresh northerly breeze died down somewhat during the onset of the eclipse, but remained sufficient during totality to cause troublesome vibration of instruments in a few cases. The seeing was otherwise remarkably good, with little scintillation. The shadow bands were inconspicuous, and noticed only by a few observers.

A very wide range of equipment was used and the time allowed for preparation on site showed a rather surprising amount of variation as well. A few cautious observers arrived at the beginning of the year, allowing themselves about eight weeks before the eclipse; the majority came in the second half of January and had five or six weeks; one group reached Khartoum with only seven days in hand. 'The experience of the British-Dutch party, with which I was associated, was that about four weeks on the site were sufficient for fairly simple apparatus, but that the five weeks which before the War were usually regarded as a safe allowance are inadequate for the larger and more elaborate instruments now coming into use, especially if these require not merely erection and adjustment, but also supplementary observations in the days before and after totality, for photometric and other calibrations. In such cases seven or eight weeks are not excessive for preparation on site.

This was the first eclipse with a clear sky at which a good number of both optical and radio observers were working practically side by side. Observations of solar radio noise were undertaken by two groups : an American party from the Naval Research Laboratory, Washington, led by Dr. J. P. Hagen, made observations in two wave-length bands at $8.5 \mathrm{~mm}$. and $10.6 \mathrm{~cm}$. respectively, while a French party from the Institut d'Astrophysique, Paris, under Dr. M. Laffineur, worked at wave-lengths $55 \mathrm{~cm}$. and $117 \mathrm{~cm}$. 'The sun was 'quiet', and it is understood that both groups obtained satisfactory records, although the details are not yet generally known. The measures should help considerably in the location of the solar levels from which the radio noise comes, and the evaluation of the physical conditions at these levels. A particularly interesting question is that of the kinetic temperature of the chromosphere, where at present there is a conflict of data. Measures at $8.5 \mathrm{~mm}$. should refer to the upper chromosphere, somewhat less than $10,000 \mathrm{~km}$. above the photosphere, and earlier radio results have pointed to a temperature not far from that of the photosphere itself. On the other hand, the only reasonably accurate optical measures of chromospheric line-widths available until now suggest a considerably higher temperature. In the hope of improving these, I obtained photographs of the chromospheric spectrum in two regions, $\lambda \lambda 5550-$ $6040 \mathrm{~A}$. at second contact, and $\lambda \lambda 3430-4110 \mathrm{~A}$. at third contact, using the second order of a 6 -in. concave grating in a Wadsworth mounting. The spectrograph was in a pit in the ground for thermal insulation; it was used as an ordinary laboratory slit instrument, and gave a dispersion about $2 \frac{1}{4} \mathrm{~A} . / \mathrm{mm}$. The photographs appear to be satisfactory, but critical examination and discussion will take many months. An alternative approach to the line-width question was followed by Prof. H. Brück and Dr. D. A. Jackson (Dublin), who used a Fabry-Perot interferometer in combination with a standard Hilger quartz spectrograph. In view of the great technical difficulties, the complexity of the chromospheric spectrum, the brevity of the allowed time of exposure, and the difficulty of maintaining the adjustment of an interferometer outdoors, in a climate with grilling sunshine and a very high diurnal range of temperature, this work must be classed as a bold enterprise. Nevertheless, a first 
examination of the exposures indicates success. The problem of interpreting the fringe patterns promises to be complicated, but the results should be of great interest.

The long-standing problem of the distribution of line emission with height in the chromosphere was tackled very thoroughly by two parties. Dr. J. Houtgast and Mr. C. Zwaan (Utrecht), using objective prisms, obtained a fine series of spectrograms at both second and third contacts. They calibrated these very carefully, so as to permit not only reliable measures of the distribution of intensity with regard to height, but also measures of the absolute brightness of the chromosphere in any selected line of its spectrum. A programme closely similar in principle, although very different in practical detail, was followed by Dr. John W. Evans (High Altitude Observatory, Colorado) and his associates. They also used slitless spectrographs, with three gratings covering a wide range of spectrum from ultra-violet to infra-red, and with (for an eclipse instrument) elaborate control gear for making exposures, changing the films, etc. It is understood that much valuable material was collected, although not enough is known of the results for comment to be made here.

There was a great concentration on problems relating to the corona. Regular daily observations with coronagraphs at mountain stations have added much to our knowledge of the lower corona during the past ten years; but far from supplanting eclipse observations, they have served rather to stimulate eclipse work, and incidentally to encourage a breakaway from the unimaginative eclipse routines of the past. Prof. M. Waldmeier (Zurich) led a large Swiss party of about a dozen observers, operating a considerable number of instruments, nearly all devoted to the corona. The underlying thought of this programme was that the corona must now be regarded. as variable in some-perhaps most-of its physical characteristics, so that the validity of combining data from different observers at different eclipses may be questioned. The aim, then, was to make simultaneously as many different observations as possible, to get an accurate and comprehensive picture of the corona as it was at one particular moment, employing the usual techniques of photometry, polarimetry, spectroscopy, etc. Prof. Waldmeier has described his results as excellent.

Coronagraphs operating in full daylight are able to observe only the inner corona, and owing to the increase of scattering in the earth's atmosphere, their efficiency falls off with decreasing wave-lengths. Eclipse programmes to-day tend therefore either to an examination of the low corona with the view of testing the reliability of coronagraph results, or to observation particularly of those features inaccessible to the coronagraph. With this second purpose in mind, the spectrum of the inner corona was examined down to the atmospheric limit in the ultra-violet by the late Dr. B. Lyot (Paris), using a spectrograph with two semicircular slits, covering between them much of the field around the sun. Other French observers, from the Institut d'Astrophysique (MM. Pecker, Michard, Dollfus, Mme. d'Azambuja) directed their attention to the outer corona, attempting to obtain its spectrum, and also to photograph it through polarizing screens in red and in infra-red light, as far out as possible. They also photographed the corona with a Lyot filter, in light from its green and red emission lines respectively. All these observers obtained a considerable measure of success, some of their material being outstandingly good.

Two important new methods of observation were tried out for the first time. Dr. I. H. Abd-El-Rahman (Helwan) scanned the outer corona, using a photomultiplier as light receiver, with the intention of measuring the light distribution with regard to position angle around the sun, and of obtaining also a measure of the polarization. His apparatus gave about half of the observations he had hoped to get, a commendable result for a new and hitherto untried instrument. Dr. D. E. Blackwell (Cambridge) measured the relative brightness of the corona in the infra-red at a wave-length about $2 \mu$ and in the violet at about $0.4 \mu$, using respectively a lead sulphide cell and a photomultiplier as receivers. $\mathrm{He}$ succeeded in obtaining satisfactory readings at a number of points out to a distance about 3.5 radii from the limb, and will be able to extract valuable information about the relative importance of the $K$ - and $F$-coronas.

Photographic photometry of the corona in polarized light was tackled in a very thorough manner by Dr. H. von Klüber (Cambridge), and an excellent series of photographs was obtained. The inner corona was photographed on a large scale, again for surface photometry, by Dr. F. Haddock (Washington) and by Prof. M. R. Madwar (Helwan). Prominence spectra were photographed successfully by both Prof. H. Zanstra (Amsterdam) and Dr. G. Righini (ArcetriFlorence). Prof. G. van Biesbroeck (Yerkes) photographed the star field around the sun, for measurement of the Einstein shift. with a new arrangement to allow a comparison star field to be photographed simultaneously.

This article is not a complete record of all those who observed the eclipse; but two other parties must be mentioned, namely, a large group sponsored by the U.S. Air Force, under the leadership of Dr. F. J. Heyden, S.J. (Georgetown, D.C.), and the other a smaller group from the Royal Greenwich Observatory, under Dr. R. d'E. Atkinson. These had geodesy rather than astrophysics in mind, being engaged in precise measurement of relative positions on the earth's surface by accurate observation of the local circumstances of the eclipse. The American observers, distributed in small groups from the west coast of Africa (Libreville) right across the continent and on into Saudi Arabia, used photoelectric equipment for measuring the light from the sun in the partial phases near totality. The Greenwich observers at two stations in the Sudan and two in Kuwait and Iraq respectively, in each case near the edge of the totality belt, took cine-photographs of the crescent of the sun near totality, following the same method as was successfully used in Kenya in 1947. Clouds in Iraq and a certain amount of instrumental trouble in the Sudan hampered their work, but partial success was nevertheless attained. The American results are not yet available. The photometric method seems likely to be less accurate than the direct geometrical approach, but has the advantage of giving results even in a cloudy sky.

All expeditions in the Sudan had reason to be grateful for help received from several departments of the Sudan Government. Special mention should be made of the Civil Secretary's Office, where Mr. H. Colville-Stewart acted as an extremely efficient liaison officer, of whose services all eclipse parties made great use. The British Army and the R.A.F. acted as host to several parties, and gave a considerable 
amount of material assistance as well. A good deal of helpful interest was shown also by the staff of Gordon College and by private residents in Khartoum.

To an observer with some experience of pre-war eclipse expeditions from Great Britain, remarkable features of the recent eclipse. were the growth in size and elaboration of the instruments used, and the lavish scale of expenditure of some expeditions. As everyone who tries it soon discovers, to make a scientific instrument work well in the open air, exactly at a given time, under conditions which cannot be reproduced beforehand, and perhaps in an extreme climate too, is far more difficult than to use it in an ordinary laboratory. Increased complexity of eclipse instruments seems inevitable, as problems and techniques develop, and in consequence the demands upon eclipse observers can now be sometimes rather severe. One result, already apparent, is that the ratio of observers to instruments, sometimes less than unity before the War, is tending to increase to two or three or more, while, as already noticed, the time allowed for preparation on site is tending to get longer.

The other point is of more local significance. British expeditions are at present financed chiefly by Government grants from the Royal Society, made on the recommendation of the Joint Permanent Eclipse Committee of the Royal Society and the Royal Astronomical Society. These grants are very limited in amount and are quite inadequate when more than one expedition is proposed. It is no longer possible to look to private individuals for subsidies, while British universities in general have no funds from which any appreciable contribution can be made. At the recent eclipse the Greenwich parties were paid for by the Admiralty, but even with this included, British expenditure amounted to only about one per cent of the reputed American expenditure. The Joint Permanent Eclipse Committee does excellent work within its means, and it is not necessary that British eclipse funds should be increased a hundredfold-nor indeed is it likely that with such an increase the results would be related linearly to expenditurebut it is suggested that some means should be found of financing eclipse expeditions from Great Britain more liberally, especially now that radio astronomers are in the field as well as the traditional optical observers.

${ }^{2}$ Stratton, F. J. M., Nature, 168, 259 (1952).

\section{SANTIAGO RAMÓN Y CAJAL (1852-1934)}

$\mathrm{P}$

ROBABLY the greatest neurohistologist of his generation, Santiago Ramón y Cajal, son of a surgeon, was born in Petilla de Aragon a century ago, on May 1, 1852. After obtaining from the University of Zaragoza at the age of twenty-one a licence to practise medicine, he saw military service with the army medical corps in Cuba. In 1879 he was appointed director of the medical museum at Zaragoza, in 1883 professor of anatomy at Valencia, and in 1887 professor of histology and pathological anatomy at Barcelona. Five years later he was called to the corresponding chair at Madrid, from which he retired in 1922. For many years he was in charge of the Madrid Institute, which bears his name. His "Trabajos del Laboratorio de Investigaciones biológicas de la Universitad de Madrid" was influential in making known to the world the work of Spanish men of science.

In 1889 Ramón y Cajal improved Golgi's chromesilver stain, which he applied to the whole nervous system and which led to his doctrine of the neurones. Using a photographic technique, he showed that all nerve cells are discrete units and that the cells of the grey matter are not organized as a network, as had previously been assumed. His name has become attached to some six staining methods, to the olfactory area, to the commissural nucleus, and to the horizontal cells of the cortex. Among his other classic contributions to neurology may be mentioned his discovery of the optic chiasma and of the innervation of the retina; his elucidation of the histology of degeneration and regeneration of nerve tissue; his modernization of the study of gliomata; and his pioneer use of colour photography. Shortly before his death on October 17, 1934, Ramón y Cajal reviewed and re-edited his first work on the neurone. He supervised the translation of his most important books, and his "Histology of the Nervous System in Man and Vertebrates" remains to this day the most complete and eccurate account of the microscopic anatomy of the nervous system.

Ramón y Cajal's interests were wide. He was a talented artist, and his extra-professional writings, such as his "Charlas de café" (1920), reflect his philosophic bent, his humanity, and his Latin pessimism. He sought no honours, but regarded his election as a foreign member of the Royal Society of London and his Nobel Prize for Medicine and Physiology, which he shared with Golgi in 1906, as a tribute to Spanish scientific research.

A long obituary notice of Ramón y Cajal appeared in Nature of December 8, 1934, p. 871, contributed by "C. S. S.", initials which are easily recognized as being those of one of the 'immortals' of physiology who himself died but a short time ago.

\section{OBITUARIES}

Sir Charles Sherrington, O.M., G.B.E., F.R.S.

Sir Charles Sherrington, formerly Waynflete professor of physiology in the University of Oxford, and president during 1920-25 of the Royal Society, died on March 4 at the age of ninety-four. Among his many distinctions may be mentioned the Copley Medal (1927) and a Royal Medal (1905) of the Royal Society and the Nobel Prize for Medicine and Physiology in 1932 (with Prof. E. D. Adrian); he was an honorary or foreign member of many learned societies throughout the world.

We print below some appreciations which we have received.

MorE than forty years ago Sherrington published the Silliman Lectures he had given at Yale under the title "The Integrative Action of the Nervous System", and if he had published nothing after this he would still deserve to be reckoned one of the great physiologists. He gave us a new outlook on the nervous system by analysing its operations into their simplest elements and showing how these elements are welded together. The spinal reflex is taken as the starting point, and as Sherrington's chapters succeed one another the mechanism of sense organs and nerve 